\title{
Análise da Evolução do Valor dos Financiamentos do Pronaf-Crédito (1999 a 2010): número, valor médio e localização geográfica dos contratos
}

\author{
Paulo Marcelo de Souza ${ }^{1}$, Niraldo José Ponciano², \\ Marlon Gomes $\mathrm{Ney}^{3}$ e Armando Fornazier ${ }^{4}$
}

Resumo: A desigualdade da distribuição do crédito do Pronaf, entre regiões e tipos de agricultores, tem sido apontada em vários estudos. Para investigar essa questão, a pesquisa analisa a evolução dos financiamentos do Pronaf crédito no País, mediante sua decomposição nos efeitos número dos contratos, valor médio dos contratos e localização geográfica. Os resultados permitiram concluir que, na fase inicial do Programa, houve forte aumento do número de contratos, com dispersão dos financiamentos para estados de agricultura familiar mais pobre, situados principalmente na região Nordeste. Essa expansão prosseguiu até 2006, acompanhada também, desde 2003, de aumento no tamanho médio dos contratos. A partir de então, a expansão do crédito vem se baseando exclusivamente no aumento do tamanho médio dos contratos e na crescente participação de estados de agricultura mais capitalizada em sua distribuição. Em decorrência dessa mudança, que pode estar associada com as mudanças nas normas do Programa, a distribuição dos financiamentos vem se tornando mais desigual.

Palavras-chaves: Agricultura familiar, crédito, Pronaf, distribuição.

Abstract: The inequality of credit distribution of Pronaf, between regions and types of family farmers, has been indicated in many studies. To investigate this question, the research analyzes the evolution of Pronaf credit financings in Brazil, facing its decomposition in the effects number of contracts, average value of contracts and geographic localization. It can be concluded that, in the initial phase of the Program, a great increase in the contract

1 Professor Associado da Universidade Estadual do Norte Fluminense Darcy Ribeiro (Uenf). E-mail: pmsouza@uenf.br

2 Professor Associado da Universidade Estadual do Norte Fluminense Darcy Ribeiro (Uenf). E-mail: ponciano@uenf.br

3 Professor Associado da Universidade Estadual do Norte Fluminense Darcy Ribeiro (Uenf). E-mail: marlon@uenf.br

4 Doutorando em Desenvolvimento Econômico na Universidade Estadual de Campinas (Unicamp). E-mail: armandouenf@yahoo.com.br 
number was verified, with dispersion of financings for states of poorer family farming, situated mainly in the Northeastern region in Brazil. This expansion continued until 2006, also followed, since 2003, by the increase in the average size of contracts. Since then, the expansion of the credit has been based exclusively on the increase of the average size of contracts and on the growing participation of states of capitalized agriculture in its distribution. As a result of this change, which may be associated with changes in the rules of the program, the inequality of the distribution of its financings is increasing.

Key-words: Family agriculture, credit, Pronaf, distribution.

Classificação JEL: Q14, Q18.

\section{Introdução}

Informações do Censo Agropecuário de 2006 mostram que a agricultura familiar responde por $38 \%$ (ou R\$ 54,4 bilhões) do valor total produzido pela agropecuária brasileira. Esse segmento ocupa cerca de 12,3 milhões de pessoas, o que equivale a $74,4 \%$ do pessoal ocupado no total dos estabelecimentos agropecuários (IBGE, 2009). Apesar de sua importância, pode-se dizer que até meados da década de 90 não existia nenhum tipo de política pública, com abrangência nacional, voltada ao atendimento das necessidades específicas do segmento social de agricultores familiares.

Essa política surge em 1996, com a criação do Programa Nacional de Fortalecimento da Agricultura Familiar (Pronaf), atendendo a uma antiga reivindicação das organizações dos trabalhadores rurais. Desde sua implementação, o Programa tem sido objeto de vários estudos, nos quais suas limitações e deficiências, bem como seus possíveis efeitos positivos sobre a agricultura familiar, vêm sendo abordados 5 . Paralelamente, o Programa teve mudanças em sua operacionalização, visando aumentar sua abrangência, facilitar sua adoção e adequar-se aos distintos grupos de agricultores presentes no segmento familiar.

5 Estudos como os de Kageyama (2003), Martins et al. (2006), Mattei (2006), Guanziroli (2007), Assunção e Chein (2007), dentre outros, obtiveram indícios de efeitos positivos do Programa, como aumento da área plantada, elevação do nível de investimento, do uso de tecnologia e da produtividade agrícola, bem como aumento do emprego, da renda familiar e da qualidade de vida.
Uma das principais críticas ao Programa refere-se à distribuição dos recursos entre as regiões e entre tipos de agricultores familiares. Estudos comprovaram que os estados da região Sul captam maior volume de recursos (MATTEI, 2005; GUANZIROLI, 2007). Essa região, segundo Martins, Alencar e Mendonça (2006), concentrava cerca de metade do volume de crédito do Pronaf, embora representando apenas $18 \%$ da área total cultivada da agricultura familiar. No que se refere à desigualdade da distribuição dos financiamentos entre agricultores, Silva, Corre e Neder (2007) destacaram a baixa parcela dos recursos recebida pelos agricultores pertencentes ao grupo B. Figueiredo, Silva e Santos (2006) apontaram a necessidade de redistribuição dos recursos do Pronaf, a fim de beneficiar os agricultores de renda mais baixa.

Por outro lado, estudos posteriores encontraram evidências de redução na desigualdade da distribuição dos financiamentos. Segundo Mattei et al. (2007), houve melhora na distribuição dos recursos, em decorrência da expansão do Programa para municípios que, inicialmente, não podiam acessá-los. Conforme Gasques et al. (2005), o percentual dos municípios brasileiros que não recebiam crédito do Pronaf, de 16,87\% em 2000, caiu para 10,79\% em 2004. Também Souza, Ney e Ponciano (2010) constataram, até 2006, tendência de redução na desigualdade da distribuição dos financiamentos do Pronaf crédito entre os estados.

Porém, nos anos mais recentes, a distribuição dos financiamentos voltou a se concentrar, 
favorecendo principalmente os estados da região Sul do País (SOUZA, NEY e PONCIANO, 2010). Segundo os autores, essa piora na distribuição dos financiamentos está provavelmente associada a alterações nas normas do Pronaf, que vêm possibilitando a crescente inclusão no Programa de agricultores mais capitalizados.

Conforme Aquino e Schneider (2010), o aumento do limite da renda bruta anual, para fins de enquadramento de agricultores no Programa, vem possibilitando aos agricultores mais capitalizados a apropriação de parcela crescente dos recursos. Como destacado por Bruno e Dias (2004), já a introdução do grupo D, permitindo a inserção de produtores com dois trabalhadores assalariados, contrariou o anseio das organizações dos trabalhadores rurais. Para essas organizações, isso representaria a inclusão de estabelecimentos com maior capacidade de oferecer garantias aos bancos e, portanto, a legitimação de uma lógica bancária excludente. Foi em decorrência dessas pressões que se estabeleceu, em 1997, um teto de renda bruta para enquadramento de agricultores no Grupo D, fixado em R\$27.500,00.

Porém, como destacam Aquino (2009) e Aquino e Schneider (2010), o limite de R\$ 27.500,00, que perdurou até a safra 1999/2000, ampliou-se significativamente na safra 2003/2004, com a criação do então grupo $\mathrm{E}$, atingindo $\mathrm{R} \$$ $110.000,00$ na safra 2007/2008. Na interpretação dos autores, isso "abriu as portas" do Programa para agricultores mais capitalizados e com capacidade de oferecer aos bancos garantias reais e contrapartidas, com potencial para absorver crescente fatia dos recursos, principalmente os de investimento. Como resultado, recursos financeiros são direcionados para agricultores mais capitalizados e para as regiões em que se encontram, em detrimento das regiões de agricultura familiar mais fragilizada, como é caso da região Nordeste.

Portanto, nos últimos anos vem sendo observado um processo de reconcentração da distribuição dos recursos. Embora questões conjunturais possam ajudar a explicar essa mudança, é provável que ela resulte de alterações nas normas do
Pronaf, que vem possibilitando a apropriação dos recursos por segmentos mais capitalizados da agricultura familiar. Abordar esse tema é o objetivo geral da presente pesquisa.

\section{Objetivos}

A pesquisa tem como objetivo analisar a evolução dos financiamentos do Pronaf crédito no País, no período de 1999 a 2010. Em termos específicos, visa analisar as fontes de crescimento desses financiamentos, mediante sua decomposição nos efeitos número de contratos, valor médio dos contratos e localização geográfica, para descrever as mudanças na distribuição dos recursos entre regiões e tipos de agricultores. Visando estabelecer uma possível relação entre essas mudanças e as alterações nas normas do Programa, a análise é feita em três períodos distintos: 1999 a 2002, que caracteriza o período inicial do Programa; 2002 a 2006, relativo ao advento do grupo E; e 2006 a 2010; marcado pela ampliação dos limites de renda para enquadramento no Programa.

\section{Metodologia e fonte dos dados}

\subsection{Decomposição da variação do crédito nos efeitos número de contratos, tamanho e localização dos contratos}

Para análise do crescimento da oferta de crédito, foi empregado o modelo shift-share, na forma proposta por Yokoyama, Igreja e Neves (1989). Esse modelo é usado em análises regionais sobre o crescimento de agregados econômicos, com uso frequente para explicar as fontes de crescimento da produção agrícola. No presente contexto, essa metodologia visa analisar o crescimento do volume do crédito, entendido como a resultante do comportamento de três variáveis: $\mathrm{o}$ número de contratos, o valor médio e a localização geográfica desses contratos.

Na presente situação, considerando-se que o crédito é distribuído entre $n$ atividades, para cada um dos m estados do País, o valor total do cré- 
dito para a j-ésima atividade, no instante inicial da análise, $t=0$, é dado por:

$$
V_{j 0}=\sum_{i=1}^{m} n_{i j 0} \bar{X}_{i j 0}=\sum_{i=1}^{m} \lambda_{i j 0} N_{j 0} \bar{X}_{i j 0}
$$

em que:

$V_{j}=$ valor do crédito da j-ésima atividade, em que $j=1,2, \ldots, \mathrm{n}$;

$n_{i j}=$ número de contratos para a j-ésima atividade, no i-ésimo estado, em que $i=1,2, \ldots \mathrm{m}$;

$N_{j}=$ total de contratos para a j-ésima atividade;

$\bar{X}_{i j}=$ valor médio dos contratos para a j-ésima atividade, no i-ésimo estado;

$\lambda_{i j}=$ participação da j-ésima atividade do i-ésimo estado no total de contratos da atividade.

De modo semelhante, o valor de crédito destinado à j-ésima atividade, no tempo $t=T$, é dado por:

$$
V_{j T}=\sum_{i=1}^{m} n_{i j T} \bar{X}_{i j T}=\sum_{i=1}^{m} \lambda_{j T} N_{j T} \bar{X}_{i j T}
$$

Supondo que apenas o número total de contratos para aquela atividade se modificasse entre os instantes $t=0$ e $t=T$, o crédito total de $j$ neste último período seria obtido por:

$$
V_{j T}^{N}=\sum_{i=1}^{m} \lambda_{j i 0} N_{j T} \bar{X}_{i j 0}
$$

Se, além do número de contratos para a atividade $j$, também o valor médio dos contratos se alterasse em cada estado, o total de crédito seria:

$$
V_{j T}^{N, \bar{x}}=\sum_{i=1}^{m} \lambda_{j 0} N_{j T} \bar{X}_{i j T}
$$

Finalmente, se a distribuição geográfica dos contratos $\left(\lambda_{i j}\right)$ também tivesse modificação, o total de crédito obtido seria dado por:

$$
V_{j T}^{N, \bar{x}, \lambda}=V_{j T}=\sum_{i=1}^{m} \lambda_{j T} N_{j T} \bar{X}_{i j T}
$$

A mudança total observada no volume de crédito para a j-ésima atividade, no intervalo de tempo compreendido entre os períodos $t=0 \mathrm{e}$ $t=T$, será:

$$
V_{j T}-V_{j 0}=\sum_{i=1}^{m} \lambda_{j T} N_{j T} \bar{X}_{i j T}-\sum_{i=1}^{m} \lambda_{j 0} N_{j 0} \bar{X}_{j 0}
$$

ou, escrito de outra forma:

$$
V_{j T}-V_{j 0}=\left(V_{j T}^{N}-V_{j 0}\right)+\left(V_{j T}^{N, \bar{x}}-V_{j T}^{N}\right)+\left(V_{j T}-V_{j T}^{N, \bar{x}}\right)
$$

em que:

$V_{j T}-V_{j 0}==$ variação total no valor do crédito da atividade $j$, entre os períodos $t=0$ e $t=\mathrm{T}$;

$V_{j T}^{N}-V_{j 0}=$ efeito número de contratos;

$V_{j T}^{N, \bar{x}}-V_{j T}^{N}=$ efeito tamanho médio dos contratos; $V_{j T}-V_{j T}^{N, \bar{x}}=$ efeito localização geográfica dos contratos.

Pela observação das equações (4) e (5), pode-se constatar que o efeito localização geográfica é dado por:

$$
\begin{aligned}
& \left(V_{j T}-V_{j T}^{N, \bar{X}}\right)=\sum_{i=1}^{m} \lambda_{j T} N_{j T} \bar{X}_{i j T}-\sum_{i=1}^{m} \lambda_{j 0} N_{j T} \bar{X}_{i j T}= \\
& =N_{j T}\left(\sum_{i=1}^{m} \lambda_{j T} \bar{X}_{i j T}-\sum_{i=1}^{m} \lambda_{j 0} \bar{X}_{i j T}\right)
\end{aligned}
$$

Nesta última equação, a expressão no interior dos parênteses consiste em uma diferença entre duas médias ponderadas dos valores médios dos contratos no tempo T, para a atividade $j$ do estado $i\left(\bar{X}_{i j T}\right)$, cujos pesos são as respectivas participações geográficas da atividade $\left(\lambda_{i j t}\right)$. Disso resulta que o efeito localização geográfica será positivo quando se verificar um aumento da participação, no total de contratos, de estados em que os contratos apresentam maior valor médio no período $\mathrm{T}$.

Para apresentar os resultados dos diversos efeitos explicativos na forma de taxas anuais de crescimento, utiliza-se a metodologia proposta por Igreja (1987). Multiplicando-se a expressão (7) pela expressão:

$$
\frac{1}{\left(V_{j T}-V_{j 0}\right)}
$$

tem-se:

$$
1=\frac{\left(V_{j T}^{N}-V_{j 0}\right)}{\left(V_{j T}-V_{j 0}\right)}+\frac{\left(V_{j T}^{N, \bar{x}}-V_{j T}^{N}\right)}{\left(V_{j T}-V_{j 0}\right)}+\frac{\left(V_{j T}-V_{j T}^{N, \bar{x}}\right)}{\left(V_{j T}-V_{j 0}\right)}
$$


Multiplicando ambos os lados da identidade (9) pela taxa anual média de variação no crédito da $j$-ésima atividade (r), obtém-se:

$r=\frac{\left(V_{j T}^{N}-V_{j 0}\right)}{\left(V_{j T}-V_{j 0}\right)} r+\frac{\left(V_{j T}^{N, \bar{x}}-V_{j T}^{N}\right)}{\left(V_{j T}-V_{j 0}\right)} r+\frac{\left(V j T-V_{j T}^{N, \bar{x}}\right)}{\left(V_{j T}-V_{j 0}\right)} r$

em que $r$ é a taxa anual média de variação no crédito para a j-ésima atividade, em percentagem ao ano, e cuja expressão é a seguinte.

$$
r=\left(\sqrt[\tau]{\frac{V_{j T}}{V_{j 0}}-1}\right) \times 100
$$

Retomando a equação (10), observa-se que a taxa anual de variação na oferta de crédito para a atividade $j$ é composta dos seguintes efeitos:

$\frac{\left(V_{j T}^{N}-V_{j 0}\right)}{\left(V_{j T}-V_{j 0}\right)} r=$ efeito número de contratos, em percentagem da variação do crédito em $j$;

$\frac{\left(V_{j T}^{N, x}-V_{j T}^{N}\right)}{\left(V_{j T}-V_{j 0}\right)} r=$ efeito tamanho dos contratos; em percentagem da variação do crédito em $j$;

$\frac{\left(V_{j T}-V_{j T}^{N, \bar{x}}\right)}{\left(V_{j T}-V_{j 0}\right)} r=$ efeito localização dos contratos, em percentagem da variação do crédito em $j$.

\subsection{Fonte dos dados}

Os dados sobre número de contratos e valor dos financiamentos do Pronaf Crédito, para cada
Unidade da Federação, foram obtidos nos anuários estatísticos do crédito rural, de 1999 a 2010, do Banco Central do Brasil. Os valores monetários foram deflacionados pelo IGP-DI, da Fundação Getúlio Vargas-FGV, base $2011=100$.

\section{Resultados}

\subsection{Evolução dos contratos e do valor dos financiamentos}

A Figura 1 descreve a evolução do número de contratos do Pronaf-crédito, para as linhas custeio e investimento, nas modalidades agrícola e pecuária. Pode-se observar que houve incremento do número de contratos durante a maior parte do período, até 2006. Esse crescimento se deu essencialmente na linha de investimento, principalmente na atividade pecuária. Porém, no restante da série, houve redução nos contratos para investimento e, consequentemente, no número total de contratos.

O acentuado declínio do número de contratos, verificado após 2006, não afetou significativamente o valor total do crédito. Na Figura 2, pode-se observar que esse total vem se elevando em decorrência, principalmente, do crescimento no volume de crédito para investimento. No saldo de todo o período, houve forte crescimento do volume de crédito, que praticamente tripli-

Figura 1. Evolução do número de contratos do Pronaf crédito no Brasil, por linha de financiamento, 1999-2010

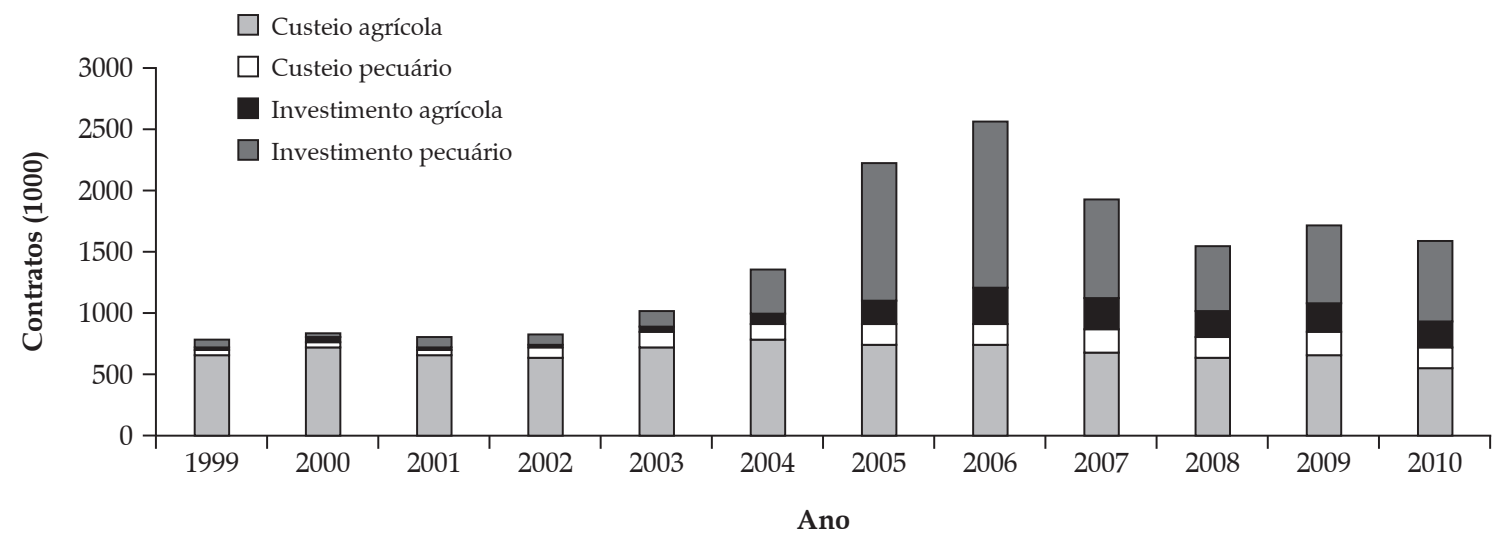

Fonte: Elaboração própria, a partir de dados do Banco Central do Brasil (2011). 
Análise da Evolução do Valor dos Financiamentos do Pronaf-Crédito (1999 a 2010):

número, valor médio e localização geográfica dos contratos

Figura 2. Evolução do valor Pronaf crédito no Brasil, por linha de financiamento, 1999-2010

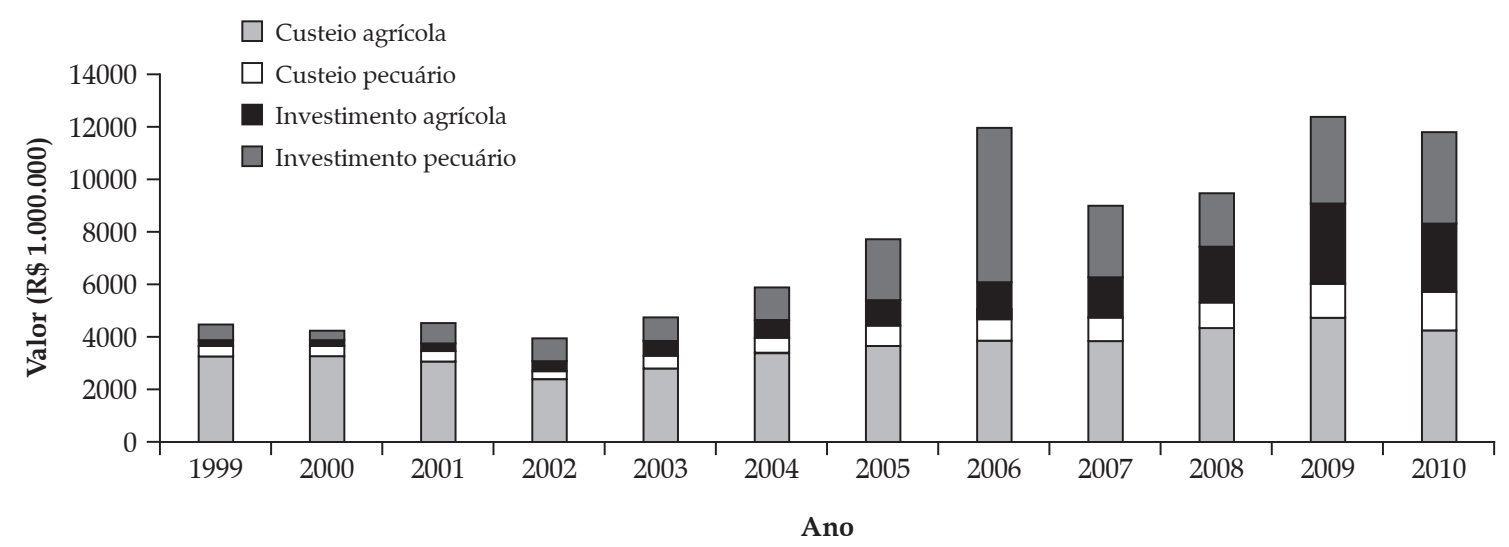

Fonte: Elaboração própria, a partir de dados do Banco Central do Brasil (2011).

cou. Além disso, a linha investimento, que inicialmente tinha pequena participação no valor total do crédito, chega, ao final do período, a representar cerca de metade desse valor.

Em termos regionais, a distribuição dos contratos passou por dois momentos distintos, conforme a Figura 3. O primeiro, até 2006, foi marcado pelo forte aumento no número de contratos, destinados, em sua maior parte, à região Nordeste. Nos anos seguintes, houve acentuada redução do número de contratos destinados ao Nordeste, o que reduziu o total de contratos e elevou a participação das demais regiões nesse montante. Nos últimos anos da série, as regiões Sul e Sudeste passam a responder, conjuntamente, por cerca da metade do total dos contratos.
As implicações das mudanças na distribuição dos contratos podem ser vistas na Figura 4. De início, observa-se que o volume de crédito manteve-se em expansão após 2006, apesar da redução no número de contratos, o que decorreu do aumento do tamanho desses contratos. Em termos distributivos, a participação da região Nordeste no valor total dos financiamentos cresceu até 2006, devido ao aumento no número de contratos a ela destinados, visto anteriormente. Nos anos seguintes, com a redução do número de contratos, a participação da região Nordeste no valor dos financiamentos diminui, ao mesmo tempo em que se elevam as participações das regiões Sudeste e Sul e, em menor proporção, das regiões Norte e Centro-Oeste.

Figura 3. Evolução do número de contratos do Pronaf crédito, por região, 1999-2010

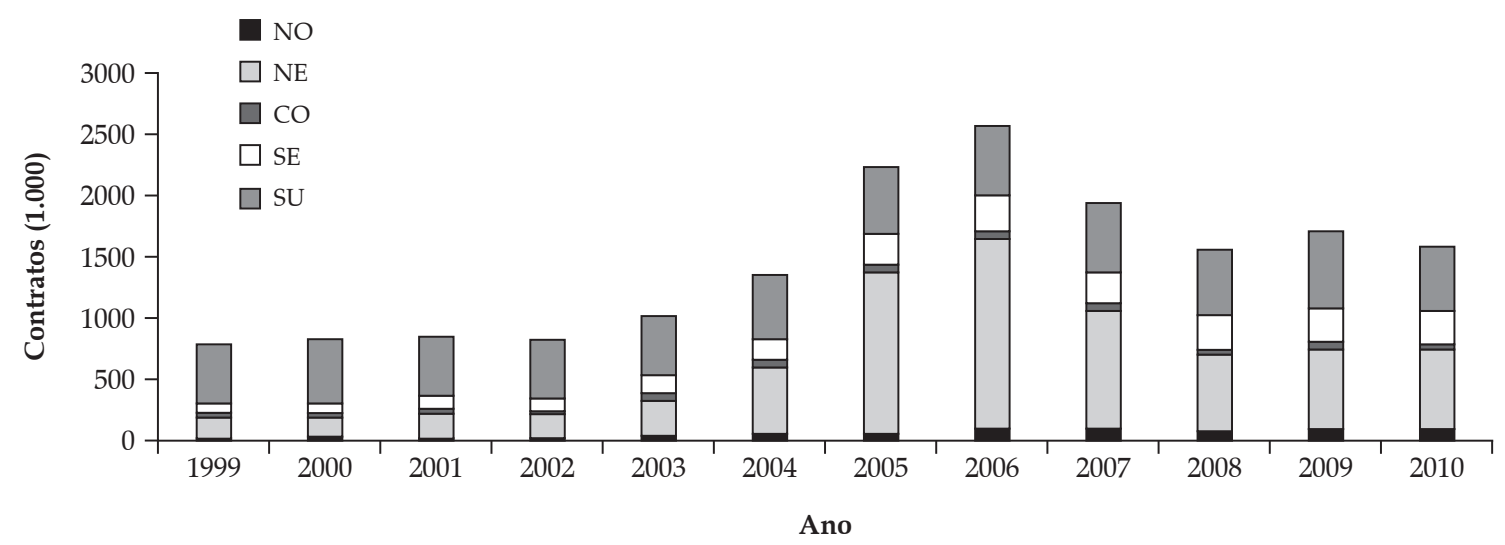

Fonte: Elaboração própria, a partir de dados do Banco Central do Brasil (2011). 
Figura 4. Evolução do valor do Pronaf crédito, por região, 1999-2010

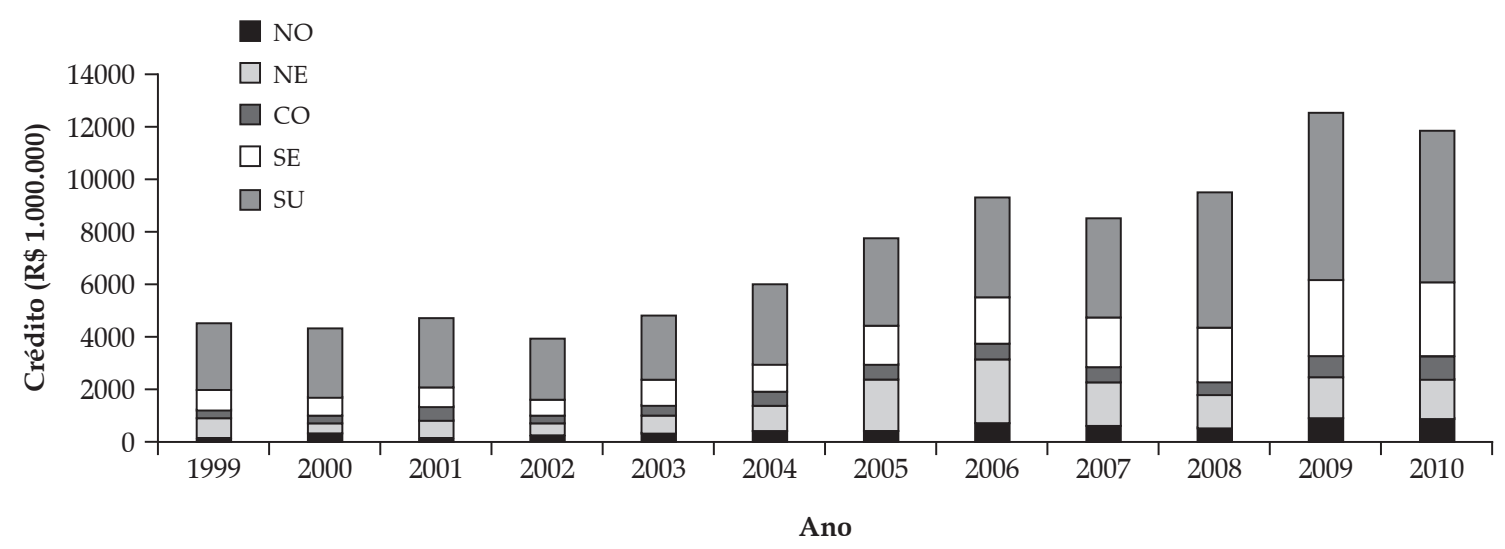

Fonte: Elaboração própria, a partir de dados do Banco Central do Brasil (2011).

Figura 5. Evolução do valor médio dos contratos de custeio do Pronaf, por região, 1999-2010

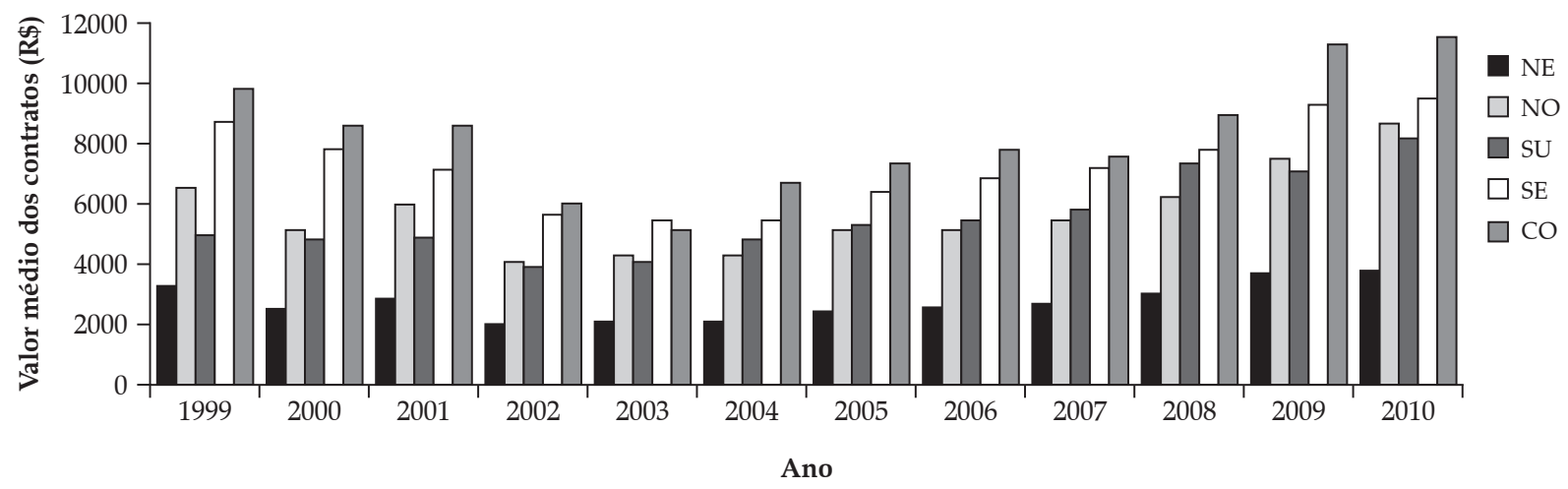

Fonte: Elaboração própria, a partir de dados do Banco Central do Brasil (2011).

Conclui-se, portanto, que, até 2006, o crescimento na oferta de crédito esteve associado ao aumento do número de contratos, direcionados principalmente a agricultores da região Nordeste. Esse processo permitiu a essa região aumentar sua participação no total dos recursos, contribuindo para reduzir a desigualdade na distribuição dos financiamentos. Esse movimento deve estar associado às mudanças na legislação, introduzidas em resposta às críticas que questionavam o excesso de burocracia e o menor acesso aos recursos por parte dos agricultores mais pobres, que culminaram em redução da burocracia e ampliação do público-alvo do Programa (SILVA, 2006). Além disso, como destacado por Guanzirolli (2007), a resistência do setor bancário público em liberar recursos a agricultores sem condições para oferecer garantias teria sido, em parte, solucionada com a atuação dos Fundos de Aval ${ }^{6}$.

Porém, após 2006, volta a se elevar a parcela das regiões Sul e Sudeste no volume de crédito, o que está associado a dois eventos entrelaçados. De um lado, cresceu a participação dessas regiões no total de contratos e, de outro, houve aumento do valor médio dos contratos, como será mostrado a seguir.

6 Por exemplo, Silva (2006) mostra que, em 1999, 85,4\% dos recursos liberados para a região Nordeste iam para o então grupo D, percentual que, em 2004, já era de apenas $13,41 \%$. Segundo a autora, essa mudança, que evidencia a dispersão dos recursos para grupos mais pobres, deve-se em grande parte aos fundos de aval vinculados ao Banco do Nordeste. 
Com relação aos contratos de custeio, notam-se valores médios mais elevados nas regiões Centro-Oeste e Sudeste, seguidas das regióes Sul e Norte (Figura 5). Os contratos destinados à região Nordeste são nitidamente inferiores aos das demais regiões. De início, houve declínio no valor médio contratado, mas, após 2003, iniciou-se um movimento persistente de elevação no tamanho dos contratos de custeio.

Os contratos de investimento têm sido, em geral, mais elevados nas regiões Norte, Sul e Centro-Oeste, conforme a Figura 6. Nessa linha, a discrepância entre o valor médio dos contratos destinados à região Nordeste e o das demais regiões é ainda maior. Observa-se também que, após 2007, o tamanho médio dos contratos passa a subir, principalmente nas regiões Sul, Sudeste e Centro-Oeste, as quais, no último ano, apresentam os contratos médios mais elevados.

No total, o valor médio dos contratos do Pronaf crédito comportou-se conforme a Figura 7. Esse valor apresentou tendência de crescimento a partir de 2003, embora essa elevação não tenha ocorrido em todas as regióes e em todos os anos. Esse movimento se acentuou nos anos finais da série, particularmente nos últimos três anos. Com a elevação do valor médio no Centro-Oeste, Sul e Sudeste, aumentou a distância entre o tamanho médio dos contratos dessas regiões e os da região Nordeste, que pouco se alterou no período.

Figura 6. Evolução do valor médio dos contratos de investimento do Pronaf, por região, 1999-2010

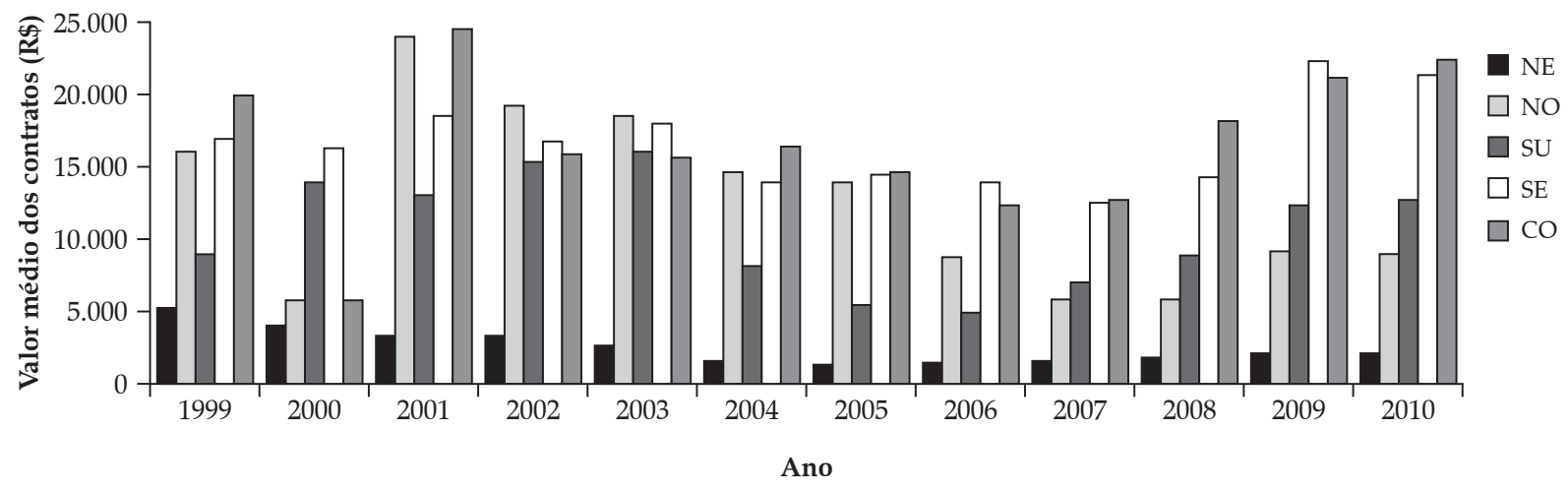

Fonte: Elaboração própria, a partir de dados do Banco Central do Brasil (2011).

Figura 7. Evolução do valor médio dos contratos de crédito do Pronaf, por região, 1999-2010

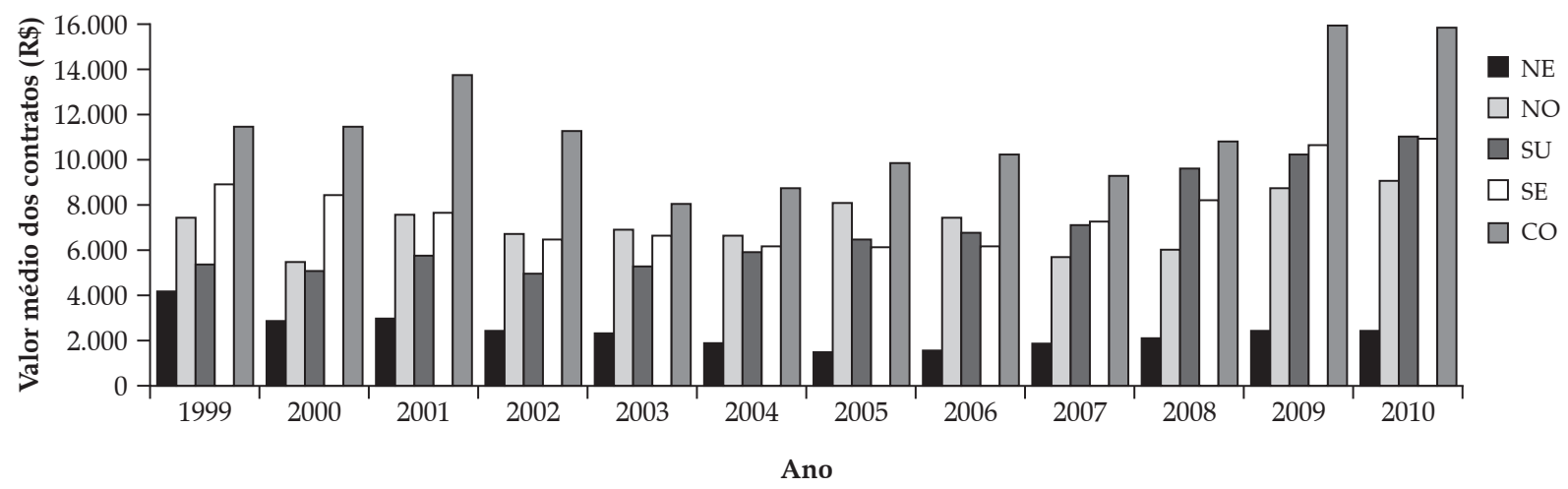

Fonte: Elaboração própria, a partir de dados do Banco Central do Brasil (2011). 


\subsection{Decomposição das taxas \\ de crescimento do crédito}

Como visto anteriormente, a evolução dos recursos do Pronaf crédito resulta do comportamento de três componentes: o número de contratos, o valor médio dos contratos e a participação de cada região na distribuição dos contratos. A influência de cada uma delas foi aferida pela decomposição da taxa de crescimento do crédito, considerando-se os períodos de 1999 a 2002, 2002 a 2006 e 2006 a 2010. Os resultados dessa decomposição, referentes ao período inicial do Programa, encontram-se na Tabela $1^{7}$.

Embora tenha ocorrido uma expansão no número de contratos nesse período, o total de crédito declinou a uma taxa média de $3,9 \%$ ao ano, em virtude da queda expressiva no valor médio desses contratos. Porém, houve diferenças no comportamento das linhas custeio e investimento. Na linha investimento, o declínio do valor médio dos contratos foi compensado pela taxa elevada de expansão no número de contratos e pelo aumento da participação, nessa linha, de estados onde os contratos eram maiores. Esse comportamento foi observado para as modalidades agrícola e pecuária.

Houve, por outro lado, redução no valor do crédito de custeio. Nesse caso, a redução do valor médio dos contratos foi também acompanhada de declínio no número de contratos, no custeio agrícola, e de reorientação desses contratos para estados com contratos menores, em ambas as modalidades. Nem mesmo a elevada taxa de crescimento no número de contratos de custeio pecuário impediu o declínio no valor total dessa linha. Há que se ressaltar que, apesar do maior dinamismo da linha investimento, a maior parte do crédito concedido nesse período foi de custeio.

\footnotetext{
7 Para alguns anos da série, não foram disponibilizados dados sobre crédito rotativo ou para custeio do extrativismo e do beneficiamento da produção. Por essa razão, não foi possível realizar a análise da evolução do crédito para essas finalidades, em determinados períodos.
}

O período seguinte foi marcado por forte expansão do crédito, alicerçada no aumento do número e do valor médio dos contratos (Tabela 2). Porém, apesar do aumento do valor médio, esse foi um período de forte expansão do Programa para regiões mais pobres e inclusão de agricultores menos capitalizados. Essas regiões, onde os contratos são menores, em média, elevaram sua participação no total de contratos, gerando efeito localização geográfica negativo. Apesar desse efeito, no total, o valor do crédito cresceu a uma taxa média de cerca de $23,7 \%$ ao ano nesse período.

A expansão do número de contratos nesse período foi bem mais expressiva na linha investimento, em ambas as modalidades, agrícola e pecuária. Além disso, o crescimento do volume de crédito dessa linha baseou-se apenas no aumento do número de contratos, uma vez que os efeitos tamanho do contrato e localização geográfica foram negativos. Houve, portanto, forte dispersão dessa linha para agricultores e estados mais pobres, reduzindo o tamanho médio dos contratos e elevando a participação desses estados no total de contratos. Em decorrência do aumento do número de contratos, os recursos para investimento cresceram, em média, $40 \%$ ao ano.

Também houve aumento do valor do crédito para custeio nesse período, a taxas de $12 \%$ e $27 \%$ ao ano, para as modalidades agrícola e pecuária, respectivamente. Nesse caso, além do crescimento do número de contratos, elevou-se também o valor médio. Esse aumento no tamanho dos contratos foi, para o custeio agrícola, o principal fator explicativo do aumento do volume de recursos. Por outro lado, foram menos importantes as mudanças na localização dos contratos nesse período, para a linha custeio.

Uma das constatações importantes a respeito desse período refere-se ao crescimento do valor médio dos contratos na linha custeio, sobretudo na modalidade agrícola. Uma interpretação é que essa mudança já reflete a criação do grupo E, com o consequente aumento dos limites de financia- 
246 - Análise da Evolução do Valor dos Financiamentos do Pronaf-Crédito (1999 a 2010):

número, valor médio e localização geográfica dos contratos

Tabela 1. Fontes de crescimento do Pronaf crédito no Brasil, 1999 a 2002

\begin{tabular}{|c|c|c|c|c|}
\hline \multirow{2}{*}{ Finalidade/Modalidade } & \multicolumn{3}{|c|}{ Efeito } & \multirow{2}{*}{ Total } \\
\hline & Contrato & Valor médio & Localização & \\
\hline Custeio Agrícola & $-0,79$ & $-8,73$ & $-0,22$ & $-9,74$ \\
\hline Beneficiamento/Industrialização & 27,71 & $-32,22$ & 133,83 & 129,31 \\
\hline Crédito Rotativo & $-7,36$ & $-9,55$ & 0,76 & $-16,15$ \\
\hline Extrativismo Espécies Nativas & - & - & - & - \\
\hline Lavoura & 1,65 & $-6,04$ & $-0,49$ & $-4,88$ \\
\hline Algodão & $-39,10$ & $-6,77$ & 1,96 & $-43,91$ \\
\hline Arroz & 6,59 & $-16,22$ & $-1,36$ & $-10,99$ \\
\hline Batata & 6,62 & $-7,46$ & $-3,27$ & $-4,10$ \\
\hline Café & 26,23 & $-30,65$ & 7,65 & 3,23 \\
\hline Cana-de-Açúcar & 44,93 & $-18,54$ & $-16,35$ & 10,05 \\
\hline Feijão & $-7,34$ & $-9,60$ & 0,64 & $-16,31$ \\
\hline Fumo & $-25,44$ & $-2,04$ & 0,10 & $-27,37$ \\
\hline Mandioca & 16,23 & $-17,82$ & $-3,30$ & $-4,89$ \\
\hline Milho & 12,37 & $-1,16$ & 0,23 & 11,43 \\
\hline Outras Lavouras & - & - & - & - \\
\hline Soja & 4,28 & 0,66 & $-0,19$ & 4,75 \\
\hline Trigo & 13,52 & $-0,65$ & $-4,27$ & 8,60 \\
\hline Outras Aplicações & $-42,23$ & $-1,32$ & $-9,65$ & $-53,20$ \\
\hline Custeio Pecuário & 30,13 & $-25,50$ & $-10,09$ & $-5,46$ \\
\hline Animais & 131,53 & $-63,83$ & $-30,05$ & 37,65 \\
\hline Beneficiamento/Industrialização & - & - & - & - \\
\hline Crédito Rotativo & 2,64 & $-13,60$ & $-0,62$ & $-11,59$ \\
\hline Outras Aplicações & $-31,09$ & 2,20 & 8,24 & $-20,64$ \\
\hline Investimento Agrícola & 8,80 & $-6,97$ & 11,52 & 13,36 \\
\hline Animais de Serviço & 43,54 & 27,44 & $-6,79$ & 64,18 \\
\hline Formação Culturas Perenes & $-6,49$ & $-10,28$ & 1,12 & $-15,65$ \\
\hline Máquinas e Equipamentos & 26,38 & 4,14 & 26,42 & 56,94 \\
\hline Melhor. Explorações & 5,58 & $-8,55$ & 19,63 & 16,66 \\
\hline Outras Aplicações & 18,23 & 3,05 & 0,44 & 21,72 \\
\hline Veículos & 47,97 & $-38,10$ & 94,63 & 104,50 \\
\hline Investimento Pecuário & 3,93 & $-4,47$ & 17,21 & 16,68 \\
\hline Animais de Serviço & 13,87 & 8,30 & 39,85 & 62,02 \\
\hline Aquisição de Animais & 13,70 & 2,67 & 13,10 & 29,46 \\
\hline Máquinas e Equipamentos & $-6,84$ & $-19,06$ & 14,53 & $-11,37$ \\
\hline Melhor. Explorações & 2,06 & $-9,46$ & 20,39 & 12,99 \\
\hline Outras Aplicações & $-9,15$ & $-9,75$ & 13,59 & $-5,31$ \\
\hline Veículos & 22,32 & $-23,96$ & 14,30 & 12,65 \\
\hline Total & 1,65 & $-6,00$ & 0,43 & $-3,92$ \\
\hline
\end{tabular}

Fonte: Elaboração própria, a partir de dados do Banco Central do Brasil (2011). 
Tabela 2. Fontes de crescimento do Pronaf crédito, 2002 a 2006

\begin{tabular}{|c|c|c|c|c|}
\hline \multirow{2}{*}{ Finalidade/Modalidade } & \multicolumn{3}{|c|}{ Efeito } & \multirow{2}{*}{ Total } \\
\hline & Contrato & Valor médio & Localização & \\
\hline Custeio Agrícola & 3,00 & 8,90 & 0,42 & 12,31 \\
\hline Beneficiamento/Industrialização & 0,47 & 16,66 & 4,15 & 21,28 \\
\hline Crédito Rotativo & $-100,00$ & - & - & - \\
\hline Extrativismo Espécies Nativas & - & - & - & - \\
\hline Lavoura & 7,99 & 13,05 & 3,61 & 24,66 \\
\hline Algodão & $-2,52$ & 12,46 & 2,88 & 12,82 \\
\hline Arroz & 2,31 & $-0,75$ & 31,22 & 32,78 \\
\hline Batata & 38,20 & 30,90 & 21,20 & 90,30 \\
\hline Café & 30,66 & 23,45 & 2,40 & 56,51 \\
\hline Cana-de-Açúcar & 36,13 & 18,81 & 3,12 & 58,07 \\
\hline Feijão & 3,96 & 9,60 & 6,61 & 20,17 \\
\hline Fumo & $-63,28$ & $-1,73$ & 1,08 & $-63,94$ \\
\hline Mandioca & 15,61 & 14,80 & 5,37 & 35,78 \\
\hline Milho & 5,91 & 13,76 & 2,36 & 22,02 \\
\hline Outras Lavouras & $-9,59$ & 0,00 & 79,02 & 69,43 \\
\hline Soja & 7,49 & 12,76 & 1,06 & 21,32 \\
\hline Trigo & 0,92 & 5,90 & 0,63 & 7,45 \\
\hline Outras Aplicações & 0,30 & 39,47 & 127,71 & 167,47 \\
\hline Custeio Pecuário & 22,31 & 5,45 & $-1,10$ & 26,67 \\
\hline Animais & 25,20 & 23,42 & 29,34 & 77,96 \\
\hline Beneficiamento/Industrialização & 512,90 & 261,18 & $-718,54$ & 55,54 \\
\hline Crédito Rotativo & $-100,00$ & - & - & - \\
\hline Outras Aplicações & 303,80 & $-99,24$ & $-162,93$ & 41,63 \\
\hline Investimento Agrícola & 124,16 & $-18,58$ & $-64,98$ & 40,60 \\
\hline Animais de Serviço & 177,90 & $-23,14$ & 1,05 & 155,81 \\
\hline Formação Culturas Perenes & 100,82 & $-52,97$ & 0,90 & 48,75 \\
\hline Máquinas e Equipamentos & 93,60 & 20,13 & $-42,75$ & 70,98 \\
\hline Melhor. Explorações & 168,66 & $-46,21$ & $-91,40$ & 31,05 \\
\hline Outras Aplicações & 77,16 & $-27,23$ & $-38,35$ & 11,58 \\
\hline Veículos & 100,75 & 93,81 & $-90,50$ & 104,06 \\
\hline Investimento Pecuário & 204,72 & $-76,05$ & $-89,76$ & 38,91 \\
\hline Animais de Serviço & 392,57 & $-200,56$ & $-88,51$ & 103,50 \\
\hline Aquisição de Animais & 257,75 & $-83,00$ & $-122,79$ & 51,96 \\
\hline Máquinas e Equipamentos & 139,19 & $-23,09$ & $-39,86$ & 76,25 \\
\hline Melhor. Explorações & 160,15 & $-67,60$ & $-79,45$ & 13,09 \\
\hline Outras Aplicações & 143,62 & $-55,05$ & $-33,98$ & 54,58 \\
\hline Veículos & 65,10 & 9,16 & 24,60 & 98,86 \\
\hline Total & 36,69 & 9,64 & $-22,65$ & 23,68 \\
\hline
\end{tabular}

Fonte: Elaboração própria, a partir de dados do Banco Central do Brasil (2011). 
mento ${ }^{8}$. Porém, o limite de renda bruta anual para fins de enquadramento no Programa, que nesse período era de $\mathrm{R} \$ 60.000,00$ (AQUINO e SCHNEIDER, 2010), ainda restringia de alguma forma a entrada de muitos agricultores nesse grupo. Com isso, houve aumento no valor médio de contratos, pela realização de contratos maiores, mas não da participação desses contratos e das regiões onde eles são predominantes, no total dos contratos. Como visto, esse foi ainda um período de efeito localização geográfica negativo, indicando a crescente participação, no total de contratos, de regióes de agricultores menos capitalizados, cujos contratos são caracteristicamente menores.

Essa situação não perdura no período seguinte, como permitem concluir os dados da Tabela 3. Esse período se distingue do anterior pela forte diminuição do número de contratos, o que não impediu que o volume total do crédito se elevasse à taxa média de 6,3\% ao ano. Tal comportamento se deu pelo crescimento do valor médio dos contratos, tal como observado no período anterior, mas também pelo crescimento da participação de regiões de agricultura familiar mais consolidada no total de contratos, fato que é evidenciado pelo efeito localização geográfica positivo.

Exceto para o custeio pecuário, cujo efeito número de contratos foi pequeno, em ambas as modalidades do investimento, bem como no custeio agrícola, esse efeito foi negativo. Para o custeio, o efeito mais importante foi o aumento do tamanho dos contratos, principal responsável pelas taxas crescimento de $2,6 \%$ e $15,7 \%$ ao ano, respectivamente, das modalidades agrícola e pecuária.

No caso do investimento, mais importante ainda do que o aumento do valor médio dos contratos foi o efeito localização geográfica. Esse resultado sinaliza uma mudança acentuada no rumo

8 Conforme, Delgado, Leite e Wesz Júnior (2011), o grupo E foi o que apresentou o maior crescimento de participação no total dos financiamentos entre as safras 2003/2004 e 2007/2008. De início com apenas $9 \%$ do total, esse grupo passou, na safra $2007 / 2008$, a responder por $23 \%$ dos recursos. dessa linha de financiamento, a qual, até então, vinha se dispersando para regiões de agricultura familiar mais pobre, contribuindo para a redução da desigualdade na distribuição dos financiamentos totais do Programa. Nesse período, o que se observa é a crescente importância de regiões de agricultura familiar mais consolidada na distribuição dos contratos de investimento, de valores unitários mais elevados.

Até aqui nada foi dito a respeito da evolução do crédito dentro de cada finalidade, cujas taxas de crescimento, bem como sua decomposição, foram exibidas nas tabelas anteriores. No custeio, conforme a Figura 8, essas mudanças implicaram, até 2003 , na perda da participação do fumo ${ }^{9}$, concomitante ao aumento da parcela representada pelo milho e pelo custeio de animais ${ }^{10}$. A partir de 2003, a proporção dos financiamentos à produção de milho, arroz, feijão e mandioca, que perdem espaço para o custeio de animais, e soja, café e trigo tem se reduzido.

Na linha investimento, a partir de 2003, a participação dos investimentos na aquisição máquinas, equipamentos e animais tem crescido, concomitante ao declínio da parcela dos investimentos na melhoria das explorações. Esse movimento se acentua após 2006, quando os investimentos passam a se destinar cada vez mais à aquisição de máquinas, equipamentos e veículos, fatores de produção associados a uma agricultura mais capitalizada, enquanto declina a participação das demais finalidades. Retornando aos resultados da Tabela 3, pode-se concluir que o

\footnotetext{
9 A lavoura de fumo absorvia parcela expressiva dos recursos, sobretudo custeio, e sua distribuição se concentrava na região Sul. Como destacado por Anjos et al. (2004), essa situação mudou com a resolução n. 3.001 do Banco Central do Brasil, de 24 de julho de 2002, que proibiu a concessão de crédito para a produção de fumo desenvolvida em regime de parceria ou integração com essas indústrias.

10 A partir de 2003, para a quase totalidade dos estados, deixa-se de fornecer informações sobre crédito rotativo. Os recursos antes destinados a essa finalidade passam a ser incluídos em outras atividades, as quais passam a contabilizar recursos que, talvez, já recebessem anteriormente na forma de crédito rotativo. Essa pode ser uma importante fonte de explicação das mudanças ocorridas na distribuição dos recursos de custeio, nesse período inicial.
} 
Tabela 3. Fontes de crescimento do Pronaf crédito, 2006 a 2010

\begin{tabular}{|c|c|c|c|c|}
\hline \multirow{2}{*}{ Finalidade/Modalidade } & \multicolumn{3}{|c|}{ Efeito } & \multirow{2}{*}{ Total } \\
\hline & Contrato & Valor médio & Localização & \\
\hline Custeio Agrícola & $-6,20$ & 7,63 & 1,12 & 2,55 \\
\hline Beneficiamento/Industrialização & $-27,53$ & $-8,87$ & 0,92 & $-35,48$ \\
\hline Crédito Rotativo & - & - & - & - \\
\hline Extrativismo Espécies Nativas & 5189,68 & $-5185,85$ & 179,26 & 183,09 \\
\hline Lavoura & $-6,66$ & 7,23 & 1,58 & 2,15 \\
\hline Algodão & $-38,17$ & $-7,20$ & 1,78 & $-43,60$ \\
\hline Arroz & $-13,82$ & 5,18 & 7,20 & $-1,44$ \\
\hline Batata & $-9,45$ & 6,23 & $-0,87$ & $-4,09$ \\
\hline Café & $-0,84$ & 10,06 & 0,80 & 10,01 \\
\hline Cana-de-Açúcar & $-6,47$ & 8,92 & 1,66 & 4,10 \\
\hline Feijão & $-14,54$ & 5,58 & 1,38 & $-7,58$ \\
\hline Fumo & 197,19 & $-209,87$ & 2,58 & $-10,09$ \\
\hline Mandioca & $-14,61$ & 3,36 & 4,25 & $-7,00$ \\
\hline Milho & $-9,65$ & 5,24 & 0,31 & $-4,11$ \\
\hline Outras Lavouras & $-2,43$ & 6,21 & 2,23 & 6,01 \\
\hline Soja & $-0,89$ & 7,34 & 0,25 & 6,70 \\
\hline Trigo & 22,22 & 13,69 & 0,60 & 36,50 \\
\hline Outras Aplicações & 4,55 & $-11,15$ & 20,38 & 13,78 \\
\hline Custeio Pecuário & 0,20 & 10,14 & 5,33 & 15,68 \\
\hline Animais & 0,46 & 9,57 & 5,48 & 15,52 \\
\hline Beneficiamento/Industrialização & $-9,05$ & 2,21 & 74,19 & 67,35 \\
\hline Crédito Rotativo & - & - & - & - \\
\hline Outras Aplicações & $-1,17$ & 30,28 & $-5,67$ & 23,43 \\
\hline Investimento Agrícola & $-4,98$ & 9,50 & 11,07 & 15,60 \\
\hline Animais de Serviço & $-10,10$ & 11,43 & $-1,42$ & $-0,08$ \\
\hline Formação Culturas Perenes & $-9,16$ & 6,68 & 1,76 & $-0,72$ \\
\hline Máquinas e Equipamentos & 6,59 & 13,93 & 8,78 & 29,30 \\
\hline Melhor. Explorações & $-11,30$ & 2,56 & 2,81 & $-5,93$ \\
\hline Outras Aplicações & $-8,01$ & 4,67 & 11,11 & 7,77 \\
\hline Veículos & 3,80 & 21,27 & 37,37 & 62,44 \\
\hline Investimento Pecuário & $-12,64$ & 6,71 & 8,65 & 2,72 \\
\hline Animais de Serviço & $-10,13$ & 3,29 & $-0,33$ & $-7,17$ \\
\hline Aquisição de Animais & $-12,41$ & 6,52 & 8,34 & 2,46 \\
\hline Máquinas e Equipamentos & $-3,96$ & 12,78 & 19,70 & 28,52 \\
\hline Melhor. Explorações & $-16,42$ & 4,92 & 6,12 & $-5,38$ \\
\hline Outras Aplicações & $-16,18$ & 7,06 & 11,89 & 2,77 \\
\hline Veículos & $-5,52$ & 19,24 & 22,18 & 35,90 \\
\hline Total & $-8,68$ & 8,20 & 6,79 & 6,31 \\
\hline
\end{tabular}

Fonte: Elaboração própria, a partir de dados do Banco Central do Brasil (2011). 
Figura 8. Distribuição dos financiamentos de custeio do Pronaf crédito, por atividade, no período de 1999-2010

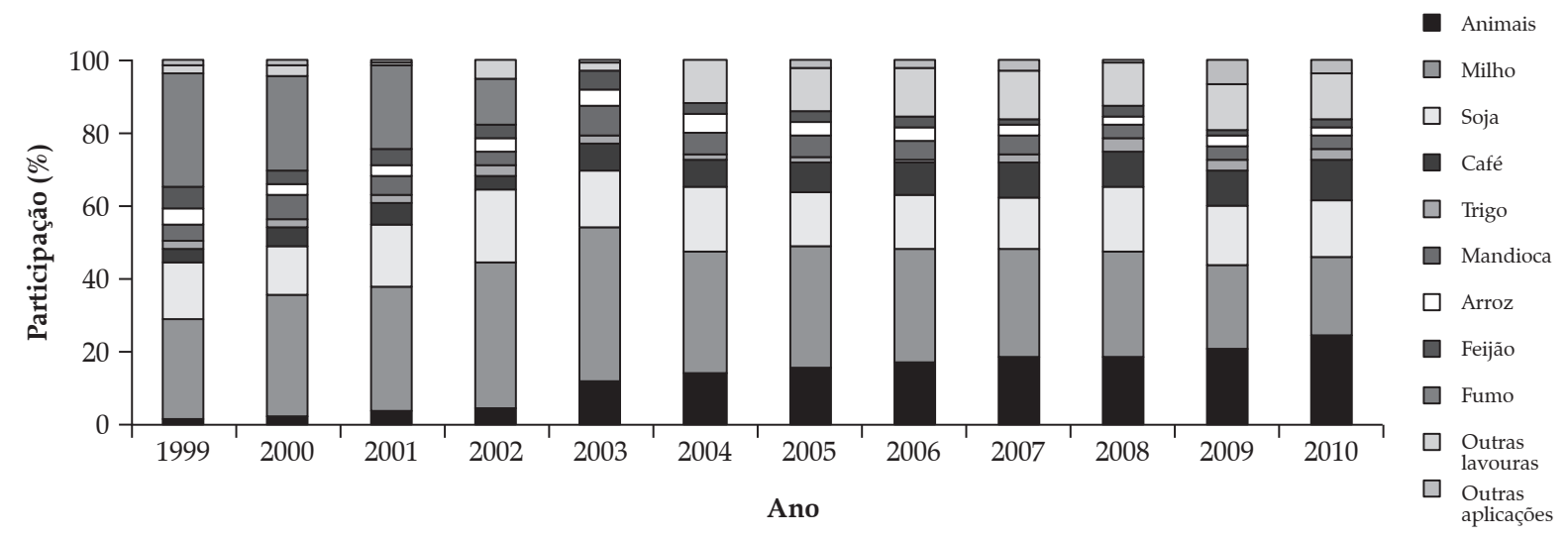

Fonte: Elaboração própria, a partir de dados do Banco Central do Brasil (2011).

Figura 9. Distribuição dos financiamentos de investimento do Pronaf crédito, por atividade, no período de 1999-2010

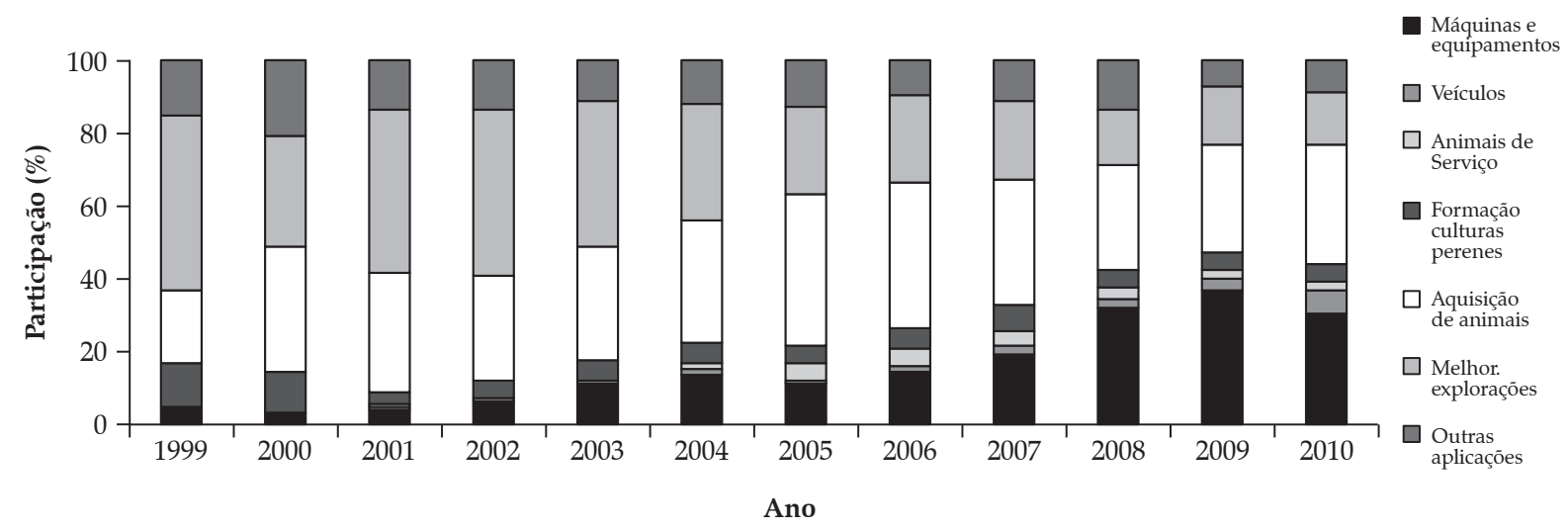

Fonte: Elaboração própria, a partir de dados do Banco Central do Brasil (2011).

crescimento da importância desses investimentos foi impulsionado principalmente pelo aumento do tamanho médio dos contratos e pela participação crescente de regiões e agricultores mais capitalizados no total de contratos.

A recente reconcentração regional da distribuição dos recursos pode ser observada na Figura 10. Essa distribuição tendia a melhorar no período inicial, com o crescimento da parcela dos recursos destinados às regiões Norte e Nordeste. Juntas, essas regiões elevaram sua participação inicial, de cerca de $20 \%$ do volume de crédito, para 34\% em 2006. Porém, essa melhora na distribuição dos recursos reverteu-se no período seguinte. Ao final do período, as regiões Sul e
Sudeste passaram a receber $73 \%$ do volume de crédito, ficando as regiões Norte e Nordeste com apenas $20 \%$ desse total. Tal reversão, como destacado por Delgado, Leite e Wesz Júnior (2011), coincide com a redução do número total de contratos do Pronaf e com o aumento de seus valores médios, a partir de 2006, fato também constatado na presente análise.

Portanto, os resultados indicam que a distribuição dos financiamentos do Pronaf tem se caracterizado pela presença de contratos maiores, o que afeta o tamanho médio dos contratos, e pela crescente participação desses contratos no número total. De um lado, esses resultados podem estar associados às mudanças nas fontes 
Figura 10. Participação regional no valor do Pronaf-crédito, em 1999, 2006 e 2010

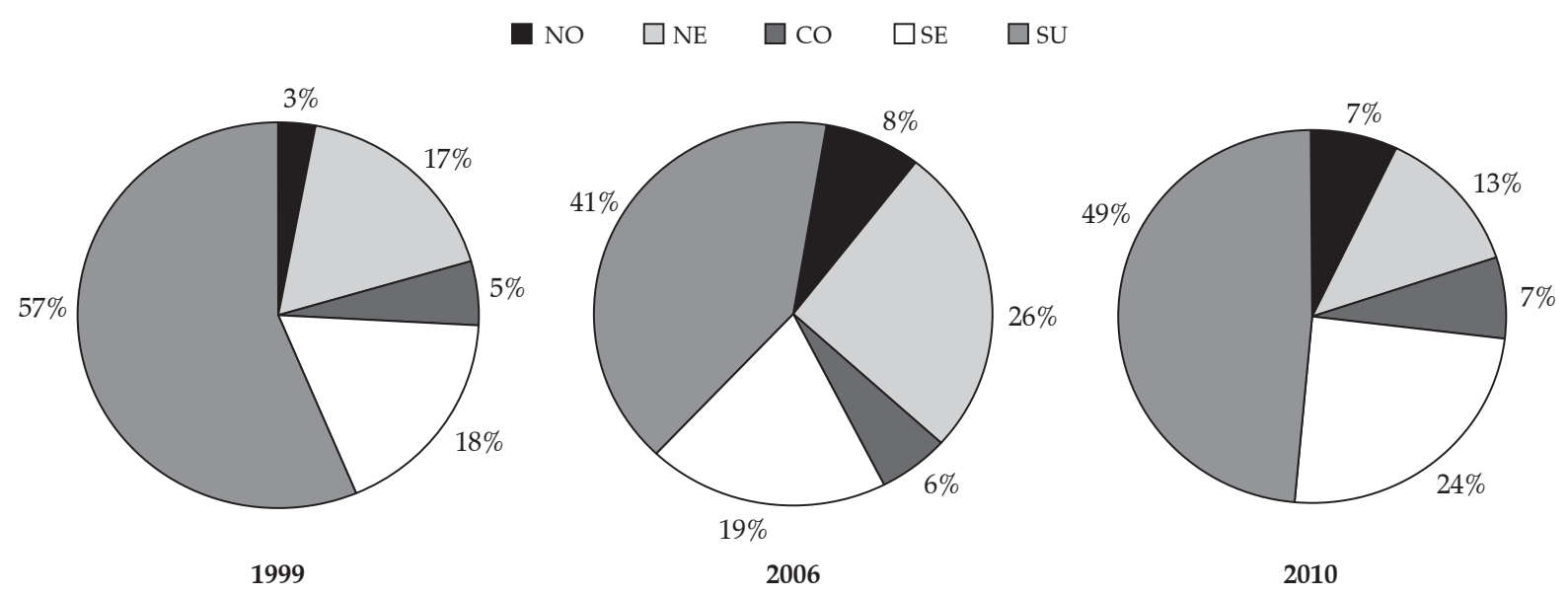

Fonte: Elaboração própria, a partir de dados do Banco Central do Brasil (2011).

que financiam o Pronaf no período. Como destacado por Delgado, Leite e Wesz Júnior (2011), em substituição aos recursos oriundos do Fundo de Amparo ao Trabalhador e do Orçamento Geral da União, de onde provinha a maior parte da dotação do Programa, os recursos obrigatórios dos bancos (MCR 6.2 e MCR 6.4) assumem importância crescente. Nesse novo cenário, os bancos, cujo papel no direcionamento dos recursos cresceu, podem optar pelo financiamento de contratos maiores e a juros mais altos, para os agricultores familiares mais capitalizados. Por outro lado, nesse novo contexto, a elevação do limite da renda bruta anual para fins de enquadramento de agricultores no Programa ${ }^{11}$, destacada por Aquino (2009) e Aquino e Schneider (2010), é forte agravante. Isso porque ela permite o ingresso dos agricultores com maior capacidade de oferecer garantias, os preferidos dos bancos, facultando-lhes apropriação de parcela crescente dos recursos.

Em síntese, os resultados aqui obtidos, ainda que não comprovem, dão força à hipótese de que as mudanças nas normas do Programa terminam por favorecer os agricultores mais capitalizados, agora também considerados familiares, que pas-

11 Em 2007, o limite de renda bruta anual para enquadramento de agricultores familiares no grupo $\mathrm{E}$ aumentou para $\mathrm{R} \$ 110.000,00$ (AQUINO e SCHNEIDER, 2010), quase o dobro do limite anterior. sam a absorver crescente parcela dos contratos e do valor dos recursos. Em última instância, essas mudanças também favorecem as regióes de agricultura familiar mais rica, em detrimento das regiões de agricultura familiar mais fragilizada, como é caso do Nordeste.

\section{Conclusões}

Buscou-se analisar a evolução da distribuição do Pronaf crédito, partindo de análises que apontam um processo de aumento da desigualdade nos últimos anos. Para a análise, foi realizada a decomposição das taxas de crescimento do crédito, nos efeitos número de contratos, tamanho dos contratos e efeito localização geográfica.

Constatou-se que o período inicial, até 2003, foi marcado pela estagnação da oferta de recursos do Pronaf crédito, que apresentou ligeira queda. Houve expansão no número de contratos, porém, com menor valor médio. A partir daí, até 2006, houve forte expansão do volume de recursos, promovida pelo aumento do número de contratos e também pelo crescimento do valor médio desses contratos. Outra característica importante desse período foi a disseminação dos financiamentos do Programa para estados com agricultura familiar pauperizada, que têm 
como característica a contratação de valores mais baixos de financiamento. Na metodologia empregada, tal processo foi evidenciado pelo efeito localização geográfica negativo, que caracterizou o período.

Para esse resultado, contribuíram as mudanças observadas na linha investimento, que se expandiu a taxas elevadas no período, mediante aumento do número de contratos. Nesse período, o valor médio dos contratos dessa linha declinou, e houve crescimento da participação de estados de agricultura familiar mais pobre no total de seus contratos. Por outro lado, o período já marca uma fase de crescimento no valor médio dos contratos de custeio. No caso do custeio agrícola, essa foi a principal fonte de crescimento do volume de recursos.

Conclui-se, portanto, que um dos possíveis impactos da criação do então grupo E nesse período foi a elevação do tamanho médio dos contratos de custeio. Porém, e provavelmente em face das limitações que o teto de renda bruta anual impunha à entrada de agricultores de maior renda na condição de beneficiários do Programa, até aí não foi verificado efeito negativo da criação desse grupo na distribuição regional dos recursos. Assim, não foi constatado crescimento da participação dos estados de agricultura familiar mais capitalizada no total dos contratos, nem mesmo dos de custeio. Ao contrário, e por efeito da forte disseminação dos contratos de investimento nos estados de agricultura familiar mais pobre, esse foi um período de efeito localização geográfica negativo, indicando a crescente participação desses estados no total de contratos.

Porém, após 2006, o número de contratos teve redução acentuada. O crescimento da oferta de crédito nesse período, que foi mais moderado do que no anterior, se baseou no aumento do tamanho médio dos contratos, e na crescente participação de regiões de agricultura familiar mais integrada no total de contratos, evidenciada por efeito localização geográfica positivo. Esse último efeito foi especialmente importante na linha investimento, assinalando a crescente participação de estados de agricultura familiar mais consolidada na distribuição dos contratos de investimento, de valores médios mais altos.

Nesse período, vem se tornando cada vez maior a participação dos investimentos na aquisição de máquinas, equipamentos e veículos, itens normalmente associados a uma agricultura capitalizada, no total dos recursos contratados nessa linha. Em síntese, os resultados aqui obtidos fortalecem a hipótese de que as mudanças ocorridas no Programa vêm contribuindo para elevar a participação dos segmentos mais capitalizados no total dos financiamentos e aumentar a desigualdade regional na distribuição desses recursos.

\section{Referências bibliográficas}

ANJOS, F. S. et al. Estudo sobre o Pronaf no estado do rio grande do sul. Revista Brasileira de Agrociência, v. 10, n. 4, p. 503-509, out./dez. 2004.

AQUINO, J. R. Avanços e limites da política de crédito do PRONAF no Brasil (1996-2008): uma reflexão crítica. In: XLVII Congresso da Sociedade Brasileira de Economia, Administração e Sociologia Rural, 2009, Porto Alegre-RS. Anais... Brasília-DF: SOBER. v. 1. p. $1-21$.

AQUINO, J. R. e SCHNEIDER, S. 12 anos da política de crédito do PRONAF no Brasil (1996-2008): uma reflexão crítica. Congresso Latino Americano de Sociologia Rural, 8, Porto de Galinhas, 2010, p. 1- 8. Anais... ALASRU, 2010.

ASSUNÇÃO, J. e CHEIN, F. Condições de crédito no Brasil rural. Revista de Economia e Sociologia Rural, Rio de Janeiro, v. 45, n. 2, p. 367-407, abr.jun. 2007.

BANCO CENTRAL DO BRASIL. Anuário Estatístico do Crédito Rural. Disponível em: <www.bcb.gov.br>. Acesso em: fev. 2011.

BRUNO, R. A. L. e DIAS, M. As politicas públicas de crédito para os assentamentos rurais no Brasil. Rio de Janeiro, 2004 (Relatório de consultoria). Disponível em: <http://www.nead.org.br/portal/nead/arquivos/ index?folder_id=4301384>, Acesso em: 27 fev. 2011.

DELGADO, N., LEITE, S. P. e WESZ JÚNIOR, V. Nota técnica sobre financiamento rural no Brasil. Rio de Janeiro: UFRJ/CPDA, out. 2011. (Observatório de Políticas Públicas para a agricultura). 11p.

FIGUEIREDO, A. M., SILVA, M. A. P. e SANTOS, M. L. Distribuição Estadual dos Recursos do PRONAF e sua 
Comparação com a Renda dos Produtores Familiares. XLIV Congresso SOBER. Anais... Fortaleza-CE, julho de 2006.

FUNDAÇÃO GETÚLIOVARGAS. FGVIBRE. Disponível em: <http://portalibre.fgv.br/>. Acesso em: jan. 2000.

FUNDAÇÃO INSTITUTO BRASILEIRO DE GEOGRAFIA E ESTATÍSTICA. Anuário Estatístico do Brasil, 1970-94. Rio de Janeiro: FIBGE. [S. d.]. Não paginado.

GASQUES, J. G. et al. Agricultura familiar - PRONAF: análise de alguns indicadores. XLIII Congresso da Sociedade Brasileira de Economia e Sociologia Rural. Anais... Ribeirão Preto, 2005. p. 1-21.

GUANZIROLI, C. E. PRONAF dez anos depois: resultados e perspectivas para o desenvolvimento rural. Revista de Economia e Sociologia Rural, Rio de Janeiro, v. 45, n. 2, p. 301-328, abr.jun. 2007.

IGREJA, A. C. M. Evolução da pecuária bovina de corte no Estado de São Paulo no período 1969-84. Piracicaba, 1987. 197p. Dissertação (Mestrado) - Escola Superior de Agricultura "Luiz de Queiroz", Universidade de São Paulo.

INSTITUTO BRASILEIRO DE GEOGRAFIA E ESTATÍSITCA. Censo Agropecuário 2006: agricultura familiar - primeiros resultados. Rio de Janeiro: IBGE, 2009.

KAGEYAMA, A. Desenvolvimento rural: conceito e um exemplo de medida. XLII Congresso da Sociedade Brasileira de Economia e Sociologia Rural.Cuiabá/MT. Anais... 2003.

MARTINS, A. J., ALENCAR, J. R. e MENDONÇA, E. C. O crédito do Programa Nacional de Fortalecimento da Agricultura Familiar (PRONAF) e a eficiência técnica agrícola brasileira: uma análise para o período de 1996 a 2003. XLIV Congresso SOBER. Anais... Fortaleza-CE, jul. 2006.
MATTEI, L. et al. Uma análise dos impactos do PRONAF sobre as economias locais nas regiões Nordeste, Sudeste e Norte do Brasil. XLV Congresso da Sociedade Brasileira de Economia, Administração e Sociologia Rural. Anais... Londrina, 2007. p. 1-22.

MATTEI, L. Políticas Públicas de Fomento à Produção Familiar no Brasil: o caso recente do PRONAF. XLIV Congresso da Sober. Anais... Fortaleza-CE, jul. 2006.

NINAUT, E. S., MATOS, M. A. e CAIADO, R. C. O crédito rural no Brasil: evolução e panorama atual. Revista de Política Agrícola. Brasília, n. 3, p. 39-49, jul./ set. 2009.

SILVA, F. F. Distribuição de crédito para a agricultura familiar: um estudo a partir de um indicador de desenvolvimento rural. Uberlândia: Universidade Federal de Uberlândia, 2006 (Dissertação de Mestrado). 250p.

SILVA, F. F., CORREA, V. P. e NEDER, H. D. Estudo comparativo da distribuição de recursos do PRONAF Crédito e Infra-estrutura, nas regiões Sul e Nordeste do Brasil: uma abordagem estatística. In: ORTEGA, A. C. e ALMEIDA FILHO, N. (Org.). Desenvolvimento Territorial, Segurança Alimentar e Economia Solidária. Campinas: Editora Alínea, 2007, p. 123-158.

SOUZA, P. M., NEY, M. G. e PONCIANO, N. J. Comportamento da distribuição dos financiamentos do Pronaf entre as unidades da federação, no período de período de 1999 a 2009. Congresso da Sociedade Brasileira de Economia, Administração e Sociologia Rural, 48. Anais.... Campo Grande, 2010. Brasília: Sober, 2010.

YOKOYAMA, L. P., IGREJA, A. C. M. e NEVES, E. M. Modelo shift-share: uma readaptação metodológica e uma aplicação para o Estado de Goiás. In: CONGRESSO BRASILEIRO DE ECONOMIA E SOCIOLOGIA RURAL, 27, Piracicaba, 1989. Anais... Brasília: SOBER, 1989 , v. 1, p. 63-68. 